\title{
A Study of Emotional Intelligence of Scheduled Caste and Non- Scheduled Caste Students
}

\author{
Arun Prakash Krishna Vimal ${ }^{1}$, Dr. Smita Jaiswal ${ }^{2}$
}

\section{ABSTRACT}

The study was under taken to study the Emotional Intelligence of scheduled caste and nonscheduled caste students. Total sample consisted of randomly selected 400 students from various colleges (arts, science and commerce) of Kanpur city of Uttar Pradesh. Of these four hundred students 200 were scheduled caste and 200 were non-scheduled caste. Data was statically analysied by 'ANOVA'. The result revealed that non-scheduled caste students have better emotional intelligence than scheduled caste students.

Keywords: Emotional Intelligence, Scheduled Caste, Non-Scheduled Caste, Student.

The cultural diversity of Indian society stands a distinctive characteristic of different castes and communities. Each caste practices certain dispositions which mold and shape the product which is affected very much by the reactions from the society and its people. The whole society may be divided on the basis of caste religions wealth and region.

This cultural diversity and social discrimination how much affects the emotional intelligence? Present study was designed to find out the answer. A few numbers of studies have revealed controversial results.

Patel A. C. (2012) - Found that the level of confidence is similar for the male scheduled caste students having high and low emotional intelligence. The level of confidence is much higher for the female scheduled caste students of high school having high emotional intelligence than for the female students of the same caste and the same grade but having low emotional intelligence. The emotional intelligence is similar for the female schedule caste students having high and low emotional intelligence.

\footnotetext{
${ }^{1}$ Research scholar D V C Orai Jalaun, India

${ }^{2}$ Associate Professor, Dept. of Psychology Bundel Khand College, Jhansi, India

*Responding Author

(C) 2016 I A Vimal, S Jaiswal; licensee IJIP. This is an Open Access Research distributed under the terms of the Creative Commons Attribution License (http://creativecommons.org/licenses/by/2.0), which permits unrestricted use, distribution, and reproduction in any Medium, provided the original work is properly cited.
} 
Brar P. K. (2014) - Found that general caste students are to be higher on empathy, selfmotivation, managing relations, self-development and emotional intelligence as compared to students of scheduled caste category.

Lekhi (2005) in her study on a sample of 939 male and female adolescents found that adolescents of general category were having higher level of emotional maturity as compared to the adolescents of scheduled caste category.

Jaidka M. L. (2012) found of no significant difference in Emotional Intelligence of the Scheduled caste and Non Scheduled caste pupil teachers on their teaching competency.

Keeping all these views in mind present study was designed.

\section{Purpose}

Purpose of the study is to compare the level of Emotional Intelligence of Scheduled Caste and Non-Scheduled Caste students.

\section{Hypothesis}

It was hypothesized that there is no significant difference in Emotional Intelligence of Scheduled Caste and Non-Scheduled Caste students.

\section{Sample}

The sample consisted of randomly selected 400 students from various colleges (arts, science and commerce) of Kanpur city of Uttar Pradesh. Of these four hundred students 200 were scheduled caste and 200 were non-scheduled caste. The sample was divided into four groups on the basis of gender. All the subjects were from the same age range (17 to 25 years), socio economic status and educational level.

\section{Tools}

Assessing Emotional Scale by N. S. Schutte et al. was used to measure the Emotional Intelligence.

\section{Statistical analysis}

Result is analysis by single factor Analysis of variance 'ANOVA'. 


\section{RESULT AND DISCUSSION}

Comparison of Emotional Intelligence and its four factors of Scheduled Caste and NonScheduled Caste Students

Table No-1 showing mean and S. D. of Emotional Intelligence of scheduled caste and nonscheduled caste student.

\begin{tabular}{|c|c|c|c|c|c|}
\hline & & \multicolumn{2}{|c|}{$\begin{array}{l}\text { Scheduled Caste } \\
\text { Students }\end{array}$} & \multicolumn{2}{|c|}{$\begin{array}{l}\text { Non-Scheduled Caste } \\
\text { Students }\end{array}$} \\
\hline \multirow{2}{*}{\multicolumn{2}{|c|}{$\mathbf{N}$}} & \multicolumn{2}{|l|}{200} & \multicolumn{2}{|l|}{200} \\
\hline & & Mean & S. D. & Mean & S. D. \\
\hline \multirow{4}{*}{ 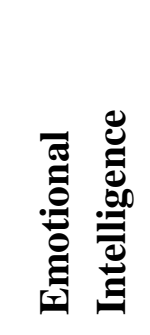 } & Perception of Emotion & 32.69 & 5.47 & 33.5 & 6.12 \\
\hline & $\begin{array}{l}\text { Managing Own } \\
\text { Emotion }\end{array}$ & 30.71 & 5.98 & 33.82 & 6.84 \\
\hline & $\begin{array}{l}\text { Managing Others } \\
\text { Emotion }\end{array}$ & 28.30 & 5.13 & 29.98 & 5.24 \\
\hline & Utilization of Emotion & 20.63 & 4.08 & 23.06 & 4.98 \\
\hline \multicolumn{2}{|c|}{ Total Mean } & \multicolumn{2}{|l|}{112.33} & \multicolumn{2}{|l|}{120.36} \\
\hline \multicolumn{2}{|c|}{ Standard Deviation } & \multicolumn{2}{|l|}{15.93} & \multicolumn{2}{|l|}{17.91} \\
\hline
\end{tabular}

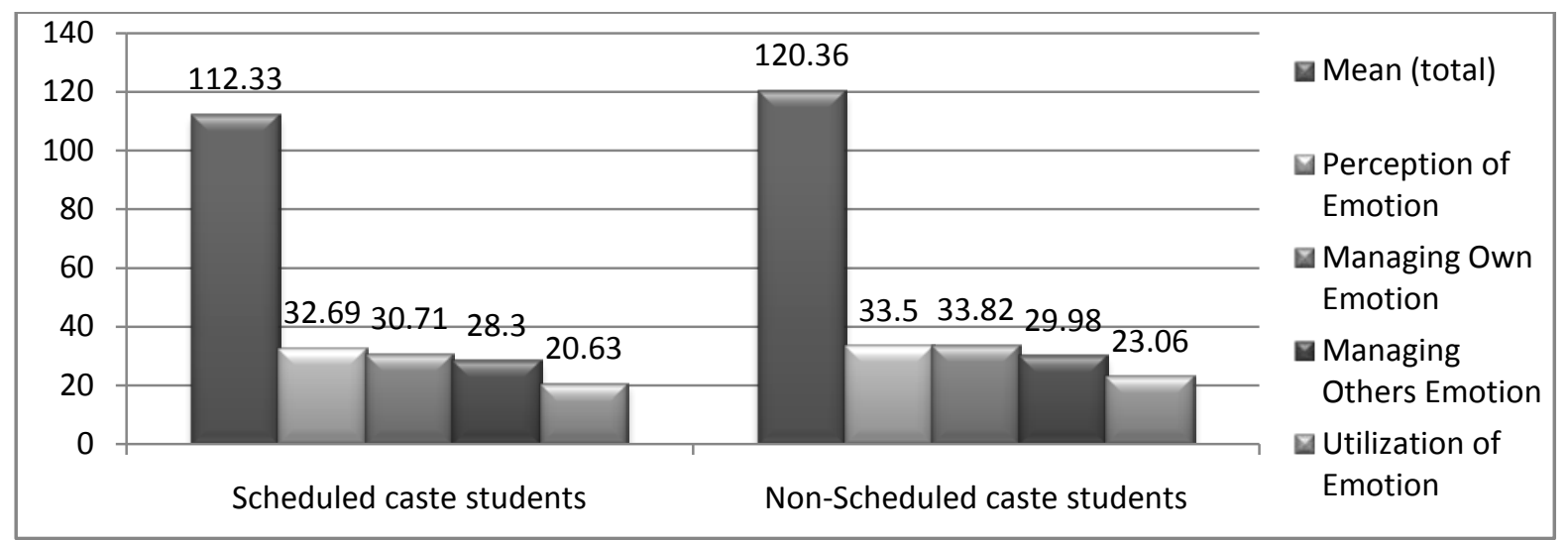

Showing the total Mean score of Emotional intelligence and its four factors on Scheduled Caste and Non-Scheduled Caste students.

Diagram shows that non-scheduled caste students have better emotional intelligence as whole (mean=120.36) than scheduled caste (mean=112.33). Non-scheduled caste students have better perception of emotion (mean=33.5) than scheduled caste (mean=32.69). Managing own emotion of non-scheduled caste students have better (mean=33.82) than scheduled caste (mean=30.71). Managing others emotions of non-scheduled caste students have (mean=29.98) and scheduled caste (mean=28.30). Utilization of emotion of non-scheduled caste students have better (mean=23.06) than scheduled caste (mean=20.63). 
This finding shows that non-scheduled caste students have better emotional intelligence than scheduled caste students. They are good at perception of emotion, Managing own emotion, Managing others emotion and Utilization of emotion.

Table No. - (2) ANOVA Summary

In this section an attempt has been made to find out the effect of caste on Emotional Intelligence. Single factor design was used and analysis of variance was calculated.

\begin{tabular}{|l|l|l|l|l|}
\hline $\begin{array}{l}\text { Sources of } \\
\text { variation }\end{array}$ & Sum of Square & d. f. & Mean square & F-Ratio \\
\cline { 1 - 4 } $\begin{array}{l}\text { Between } \\
\text { groups }\end{array}$ & 6456.12 & 1 & 6456.12 & \multirow{2}{*}{$22.46>.01$} \\
\cline { 1 - 4 } Within groups & 114387.96 & 398 & 287.41 & \\
\hline & 120844.08 & 399 & & \\
\hline
\end{tabular}

Significant level at $.05=>3.86 \& .01=>6.70$

Table No. (2) Reveals that caste significantly affect Emotional Intelligence (F-Ratio=22.46, Significant at .01level). Thus the hypothesis stating that 'there is no significant difference in emotional intelligence of scheduled caste and non-scheduled caste students' is rejected.

\section{CONCLUSION}

There is a significant difference between emotional intelligence of scheduled caste and nonscheduled caste students. This finding revealed that Emotional intelligence of non-scheduled caste students was better than scheduled caste students and significant difference between nonscheduled caste and scheduled caste students was found.

\section{REFERENCE}

Brar Paramjeet Kaur (2014) http://www.ijeie.in/index.php/articles/current-volume/vol-3-issue-2mar-2014/179-a-study-of-emotional-and-social-intelligence-of-general-and-scheduledcaste-...students.

Jaidka M. L. and Passi Viplove (2012) ISSN: 2278-7690 International Journal of Research In Education Methodology www.cirworld.com Council For Innovative Research Vol. 1, No.3, October, 2012.

Lekhi, Vanita. (2005). A Study of Emotional Maturity of adolescents in relation to cognitive and non-cognitive variables. Unpublished doctoral dissertation, Panjab University, Chandigarh.

Patel Asmitaben Chandrakantbhai. ( 2012) Golden Research Thoughts Volume 2, Issue. 5, Nov. 2012 ISSN:-2231-5063

Website: www.wikipedia.org 